Pages 67-86 in Willem B. Drees, ed., Is Nature Ever Evil? Religion.
Science and Value, London: Routledge, 2003.

\author{
8 \\ NATURALIZING AND
SYSTEMATIZING EVIL
}

Holmes Rolston, III

A common approach de-naturalizes evil - takes the evil out by claiming that natural things just are, without value being either present or absent. If one asks whether a tree is sad or glad, one is misunderstanding trees. If one asks whether evolution is good or evil, one is using irrelevant categories. Nature is a neutral substrate. Natural processes and products have the standing possibility of valuation or disvaluation when humans come on the scene. But matters of fact have to be kept in a different realm from matters of value.

This view is plausible for moral evil, in the strong sense of culpably depraved. Neither is nature morally praiseworthy. We humans do not take our moral standards from nature, nor should we fault nature as though it were moral. That is a category mistake.

My inquiry is about nonmoral evil, in the weaker sense, of events and processes, which, though not culpable agents, are bad, harmful, cruel, injurious. Here, too, often nature just is. When Comet Shoemaker-Levy crashed into Jupiter in 1994 and upset the flow bands, I was not prompted to ask questions of good and evil. There does not seem to be anything evil out there in space. The place to look is here on Earth. Orcas catch sea lions for food, and play with them, tossing the struggling lions into the air, prolonging their agony. I do not fault the killer whales, but I might ask whether the nature is evil that, through natural selection, results in the nature of such beasts.

I am not asking whether this is the best possible world, but more modestly whether this Earth is systemically prolific at increasing biodiversity and biocomplexity, and whether the evils here integrate well into those powers. Perspective is crucial.

\title{
Physics and biology
}

But there is another side to this. Agreeing that there is bad in biology, physicists reply that their nature is not value free, but quite valuable. Looking at nature systemically, we have discovered a 'fine-tuned' universe 


\section{HOLMES ROLSTON, III}

from astrophysics to nuclear physics, and a messy one from evolutionary and ecosystemic biology. Physics has made dramatic discoveries at astronomical and submicroscopic ranges. This universe originated fifteen billion years ago in a 'big bang' and has since been expanding. From the primal burst of energy, elementary particles formed, and afterward hydrogen, the simplest element, which serves as fuel for the stars. In the stellar furnaces all the heavier atoms were forged. Some stars subsequently exploded (supernovae). The heavier elements were collected to form, in our case, the solar system and planet Earth.

Physics has discovered that startling systemic interrelationships are required for these creative processes to work. Recent theory interrelates the two levels; astronomical phenomena such as the formation of galaxies, stars, and planets depend critically on the microphysical phenomena. In turn, the mid-range scales, where the known complexity mostly lies (on Earth, in ecosystems or human brains), depend on the interacting microscopic and astronomical ranges.

Change slightly the strengths of any of the four forces that hold the world together (the strong nuclear force, the weak nuclear force, electromagnetism, gravitation), change critical particle masses and charges, and the stars would burn too quickly or too slowly, or atoms and molecules, including water, carbon, and oxygen, or amino acids (building blocks of life) would not form or remain stable.

Astrophysicists and microphysicists have joined to discover that, in the explosion that produced our universe, what seem to be widely varied facts really cannot vary widely, indeed that many of them can hardly vary at all, and have the universe develop life and mind. We find a single blast (the big bang) fine-tuned to produce a world that produces us, when any of a thousand other imaginable blasts would have yielded nothing.

How the various physical processes are 'fine-tuned to such stunning accuracy is surely one of the great mysteries of cosmology,' remarks P.C.W. Davies. 'Had this exceedingly delicate tuning of values been even slightly upset, the subsequent structure of the universe would have been totally different.' 'Extraordinary physical coincidences and apparently accidental cooperation ... offer compelling evidence that something is "going on." ... A hidden principle seems to be at work' (1982: 90, 110). Maybe we will need to draw theological conclusions, maybe not. But naturalistically, at least cosmologically, this seems to be a good system, not value free at all, but valuable, value-able, able to generate value.

In biology, by contrast, the history of life on Earth is a random walk with much struggle and chance, driven by selfish genes, although biologists have also found that in this random walk order is built up over the millennia across a neg-entropic upslope, attaining in Earth's natural history the most complex and highly ordered phenomena known in the universe, such as ecosystems, organisms, and, above all, the human mind. 


\section{NATURALIZING AND SYSTEMATIZING EVIL}

So systemically we have a case of cognitive dissonance, a physical world that seems value free in some perspectives, valuable in others, and a biological world that seems fertile but clumsy, maybe evil.

\section{Order and disorder}

Perhaps the reason why all the good is in physics and the bad in biology is that all the order is in physics and all the disorder in biology. But the matter is complex. We are not going to get, and do not want, any law that says: order, more order, more and more order. Logically and empirically, there must be an interplay of order and disorder if there is to be autonomy, freedom, adventure, success, achievement, emergents, surprise, and idiographic particularity. In a world without chance there can be no creatures taking risks, and the skills of life would be very different, if indeed life - as opposed to mechanism - were possible.

But sceptics are not so sure. Yes, molecular biology is impressive for the order it has discovered. But no, when we turn to evolutionary biology, the processes get much more disordered. Evolutionary history has located the secret of life in natural selection operating over incremental variations, with the fittest selected to survive. The process is prolific, but no longer fine-tuned. On the contrary, it is make-shift.

The evolutionary course, far from being a directionally ordered whole, or having headings anywhere in its major or minor currents, rather wanders. It wanders in the first instance due to atomic and molecular chance (both relative and absolute) and, given these chancy mutational possibilities provided from the lower levels, it wanders in the second instance due to the nonselection for anything but mere survival, without bias toward progress, improvement, or complexity. The process is aimless, so it can bring evil as readily as it does good. Biologists survey the staggering array of fossil and surviving life forms, see it as full of struggling, chance, zigzag, and groping omnidirectionality, some trials happening to work, most failing, a very few of them eventuating in the ascent of neural forms.

Nevertheless, systemically, what most needs to be explained in biology is not the disorder, but the neg-entropic ascent. Biologists are much troubled by what account to give of any systemic, constructive forces that give a slope to evolution. (One might say that, at this point, the discipline is in disorder about order.) The physical world overall moves thermodynamically downhill, but now in bioscience we need an overall upslope force, or set of forces, a sort of biogravity that accounts not only for a survival drive but for the assembling and conservation of more diverse and also more advanced forms. With the passage of time and trials, there will, by ever more probability, be ever more salient constructions of life, enormous distances travelled upward. 
Systemically, there seems a mixture of inevitability and openness, so that one way or another, given the conditions and constants of physics and chemistry, together with the biased earthen environment, life will somehow both surely and surprisingly appear. Manfred Eigen, a thermodynamicist, concludes 'that the evolution of life ... must be considered an inevitable process despite its indeterminate course' (1971: 519). Life is destined to come, yet the exact routes it will take are open and subject to historical vicissitudes.

Now we can get the biology back together with the physics. Despite the fine-tuned and systemically well-ordered nature we were sketching, there is disorder too in physics, the quantum indeterminism. Often that has no import for our native ranges of experience. Any uncertainty will be statistically, or systemically, masked out. A macro-determinism remains, despite a micro-indeterminism. Stochastic processes at lower levels are compatible with determinate processes at upper levels.

But perhaps there are sometimes gross effects. In genetics, events at the phenotypic level are profoundly affected by events launched at the genotypic level, as with point mutations or genetic crossing over, affected by radiation subject to quantum effects. This may affect regulatory molecules, as when allosteric enzymes, which amplify processes a million times, are in turn regulated by modifier molecules, of which there may be only a few copies in a cell, copies made from a short stretch of DNA, where a few atomic changes can shift a whole reading frame. Indeed, by the usual evolutionary account, the entire biological tale is an amplification of increments, where microscopic mutations are edited over by macroscopic selective processes. These increments are most finely resolved into molecular evolutions.

If we turn from the random to the interaction possibilities in physics, we gain a complementary picture. Nature is not just indeterminate in random ways but is plastic enough for an organism to work its program on. An organism can coagulate affairs this way and not that way, in accord with its cellular and genetic programs. The macromolecular system of the living cell is influencing by its interaction patterns the behaviour of the atomic systems. The organism is fine-tuned at the molecular level to nurse its way through the quantum states by electron transport, proton pumping, selective ion permeability, DNA encoding, and the like. The organism via its information and biochemistries participates in forming the course of the micro-events that constitute its passage through the world.

The organism is responsible, in part, for the micro-events, and not the other way round. The organism has to flow through the quantum states, but the organism selects the quantum states that achieve for it an informed flow-through. The information within the organism enables it to act as a preference sieve through the quantum states, by interaction sometimes causing quantum events, sometimes catching individual chance events 


\section{NATURALIZING AND SYSTEMATIZING EVIL}

which serve its program, and thereby the organism maintains its life course.

The organism is a whole that is program-laden, a whole that executes its lifestyle in dependence on this looseness in its parts. There is a kind of downward causation which complements an upward causation, and both feed on the openness, if also the order, in the atomic substructures. The microscopic indeterminism provides a looseness through which the organism can steer itself by taking advantage of the fluctuations at the micro levels.

These organisms, over time, maintain themselves in their species lines. Adaptation is imperfect, but if it were perfect evolution would cease, nor could life track changing environments, nor could we have evolved to where we are. It is the imperfection that drives the world toward perfection, the disvalue that is necessary in the search for more value. Natural selection requires disvalues in its exploration for values, but selects against them, to leave the values in place, so far as this is possible under local genetic and ecological constraints.

Now a different perspective on this earthen stew strikes us. Complexity requires multiple distinct parts with multiple connections. Too much distinctness yields disorder, chaos, contingency. Too much connection yields rigidity, determinism, order. Complexity must be situated between order and disorder, or 'at the edge of chaos,' or, we might say, 'on the edge of evil' on either side. A spontaneously organizing system (= 'selforganizing) is one in which, over time, such complexity has appeared, is maintained, and may continue into the future.

This churn of materials, perpetually agitated and irradiated with energy, is not some problematic, indifferent, value-free substrate, but the prolific source. The neg-entropy is as objectively there as the entropy. Nor is the disordering entropy always bad, because in a world of perpetual construction there must be perpetual deconstruction. Systemically, the achievements are as real as the drifting cycles and random walks. Genetic organisms have been making biological discoveries superposed on the geomorphic and astronomical givens. Against the indifference, the results have been prolific, five million species flourishing in myriads of diverse ecosystems.

Life makes matter count. It loads the dice. Biological events are superintending physical ones. Biological nature takes advantage of physical nature. We gain space for the higher phenomena which physics had elected to leave out.

\section{Law and history}

What the random walk omits is the cybernetic, hereditary capacity of organisms to acquire, store, and transmit new information over historical 


\section{HOLMES ROLSTON, III}

time. Organisms start simple and some of them end up complex; there are trends over longer-range time scales because something is at work additionally to tracking drifting environments. The life process is drifting through an information search, locking onto discoveries. With such a conclusion we pass from a law-like world into a historical world, or more technically from a nomothetic system to an idiographic system.

The highest values are in story, not law, in history not repeatability. Only in a spontaneously generating story can there be such adventure and novelty. The familiar scientific word for this is 'evolution,' but the better word is 'history.' In physics and chemistry one seeks laws and initial conditions with which one can predict the future. But in biology any such laws become only regularities, subject to surprises. The novel discoveries, coded in the genetics, have not only revised the initial conditions, they have also revised the previous regularities. The disorder and openness generate history. The future is not like the past; there are developing story lines.

Frances Crick complains that biology has no 'elegance.' Organisms evolve happenstance structures and wayward functions that have no more overarching logic than the layout of the Manhattan subway system (Crick 1988: 6, 137-42). Stephen Jay Gould insists that the panda's thumb is evolutionary tinkering and that orchids are 'jury-rigged' (Gould 1980: 20). Evolution works with what is at hand, and makes something new out of it.

But what is so disvaluable about that? The achievements of evolution do not have to be optimal to be valuable; and if a reason that they are not optimal is that they had to be reached historically along story lines, it is more valuable to have history plus value as storied achievement than to have 'elegant' optimal solutions without history or autonomy. Organismic vitality is better than regimented simplicity. The elegance of the thirty-two crystal classes is not to be confused with the elegance of an old-growth forest.

Take Figures 8.1 and 8.2 on the following pages and suppose they looked instead like Figures 8.3 and 8.4.

Such a world would be impressive, but rather boring, less interesting than the world in which we in fact find ourselves. It would have too much system and too little adventure, too much law and no history.

Something is increasingly learned across evolutionary history: how to make more kinds and more complex kinds. This may be a truth about natural history, even if neo-Darwinism is incompetent to say much about how this happens. Cold and warm fronts come and go, so do ice ages. There are rock cycles, orogenic uplift, erosion, and uplift again. But there is no natural selection there, nothing is competing, nothing is surviving, nothing has adapted fit, and biology seems different. All those climatological and geomorphological agitations continue in the Pleistocene period more or less like they did in the Precambrian, but the life story is not the same all over again. Where once there were no species, now there are five 


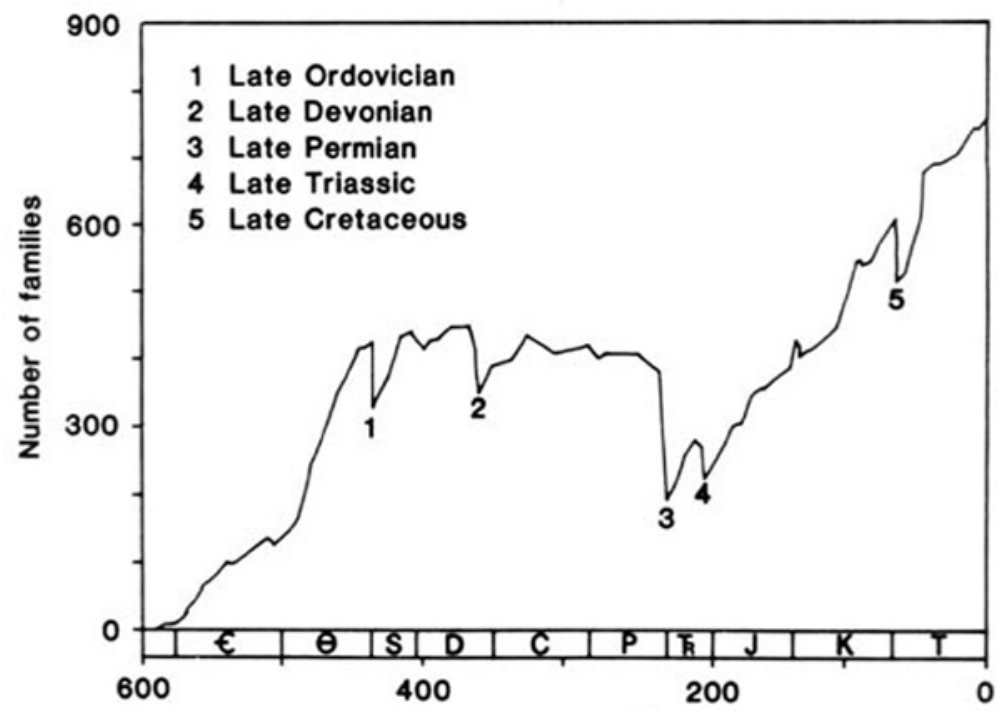

Geological time ( $10^{6}$ years $)$

Figure 8.1 Standing diversity through time for families of marine vertebrates and invertebrates, with catastrophic extinctions

Source: Reprinted with permission from Raup and Sepkoski, 1982, p. 1502. Copyright 1982 American Association for the Advancement of Science.

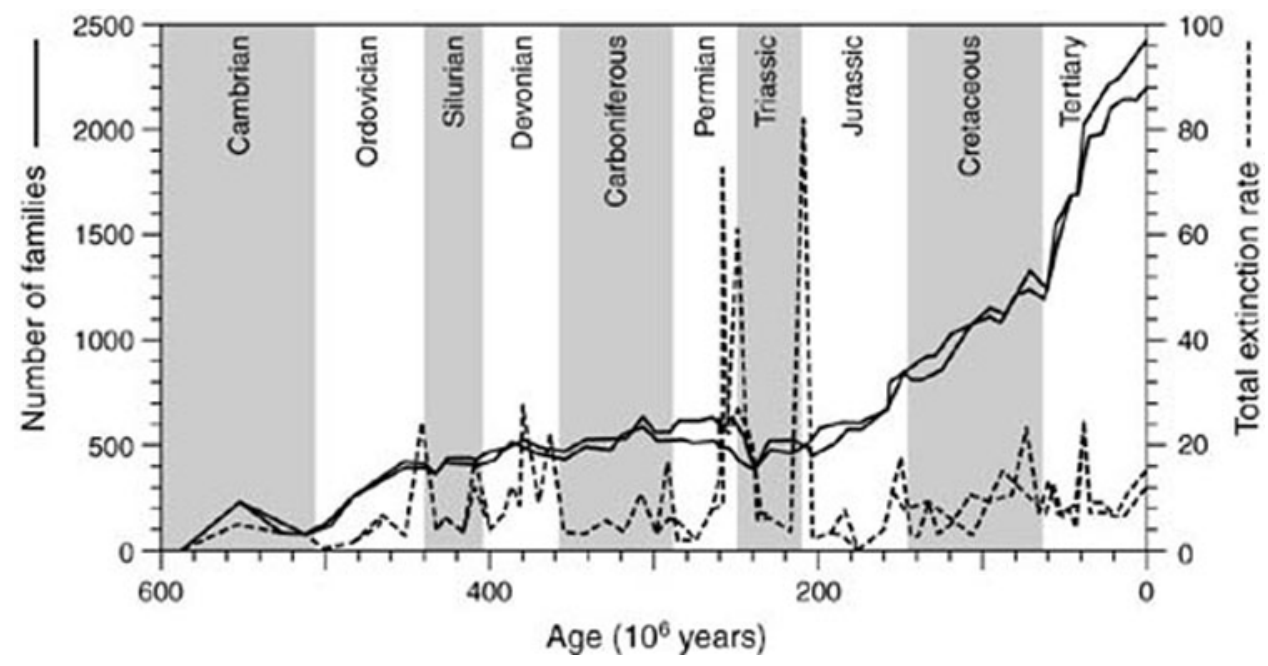

Figure 8.2 Proliferation of number of families on Earth, continuing through major extinctions. The double lines in both the number of families and the extinction rate represent maximum and minimum estimates.

Source: Reprinted with permission from Myers, 1997, p. 598, based on Nee and May, 1997.

Copyright 1997 American Association for the Advancement of Science. 


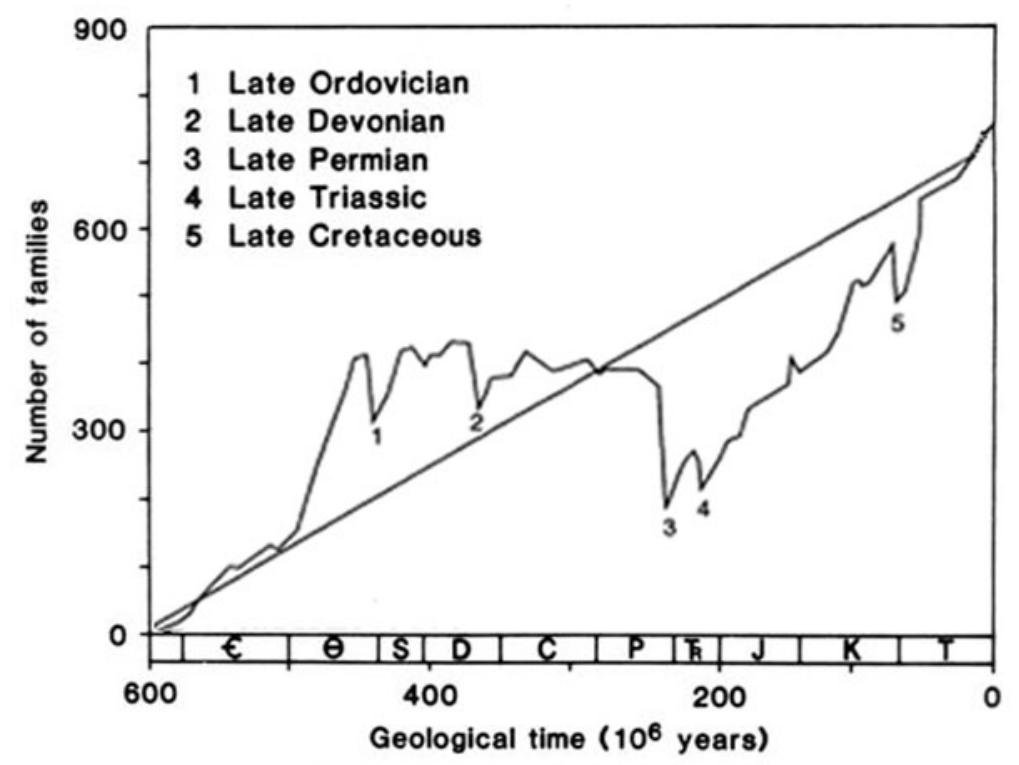

Figure 8.3 Supposed linear development of marine diversity

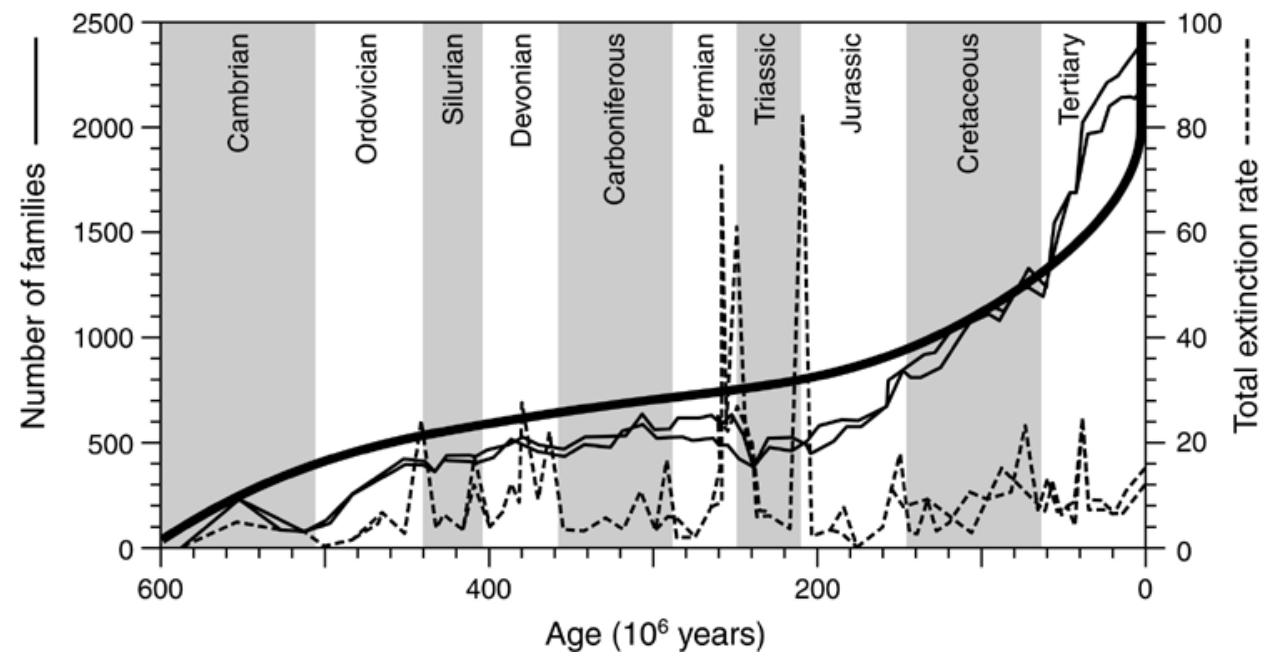

Figure 8.4 Supposed more orderly proliferation of life on Earth 


\section{NATURALIZING AND SYSTEMATIZING EVIL}

to ten million. On average, and environmental conditions permitting, the numbers of life forms start low and end high.

J.W. Valentine concludes for marine environments: 'A major Phanerozoic trend among the invertebrate biota of the world's shelf and epicontinental seas has been towards more and more numerous units at all levels of the ecological hierarchy. ... The biosphere has become a splitter's paradise' (Valentine 1969: 706). There is 'a gradually rising average complexity' (Valentine 1973: 471). The story of terrestrial life is even more impressive, because the land environment is more challenging. Reptiles can cope in a broader spectrum of humidity conditions than amphibians. Mammals can cope in a broader spectrum of temperature conditions than reptiles. Genetic and enzymatic control is surpassed by neural networks and brains; there are increases in sentient capacity, locomotion, acquired learning, communication, language acquisition, and in manipulation.

There are increases in capacities for centralized control (neural networks, brains that surpass mere genetic and enzymatic control), increases in capacities for sentience (ears, eyes, noses, antennae), increases in locomotion (muscles, legs, wings), in capacities for manipulation (arms, hands, opposable thumbs), increases in acquired learning (feedback loops, synapses, memory banks), increases in communication and language acquisition. Nothing seems more evident over the long ranges than that complexity has increased, developing historically. In the Precambrian there were microbes; in the Cambrian Period trilobites were the highest life form; the Pleistocene Period produced persons.

Francisco J. Ayala concludes: 'Progress has occurred in nontrivial senses in the living world because of the creative character of the process of natural selection' (Ayala 1974: 353). Some will find that this is a 'law' of evolution. If so, this is a startling law: incessantly generate more biodiverse and complex kinds. Such law passes over into history.

\section{Self and community}

There are 'selves' - biological organismic identities to be preserved. No such selves exist, except in communities, ecosystems. It is difficult to imagine much life without a cellular character, difficult to imagine much biodiversity or biocomplexity without life being multicellular. It is difficult to imagine much organismic differentiation and specialization of functions and skills without a characteristic 'self.' To optimize a vital 'self with a unique genetic self over a landscape of challenges, stabilities, and contingencies is really to develop a story line.

Further, one 'self cannot do it all. No 'self has 'aseity' (total self-containment). A lot of diversity, with autonomy, will mean a lot of interdependencies, feedback loops, feed forward loops, indeed a lot of feed loops. Systemically, it seems impossible - on this Earth at least - to have 
animal biology without 'feeding,' value capture, biotic resources such as energy and structural materials that were preformed outside oneself. It cannot be a bad thing for an organism to depend on another for skills or metabolisms it lacks, or else humans (who cannot photosynthesize) eating plants (which can) would be an evil. All heterotrophs of spectacular evolutionary achievement live in dependence on plants. A photosynthetic world would be a largely immobile world. In turn, autotrophs quite depend on animals for their carbon dioxide. Cycles and hypercycles build up.

The heavens are fine-tuned, and we are happy about the beauty and regularity there. But the heavens are also a world in which there is no caring. Earth, with its selves, is a world in which things can get hurt. You cannot be helped in a world where you cannot be hurt; you cannot live biologically in a world in which you cannot die; you cannot succeed in a world in which you cannot fail. Notice too that there is no community on the moon, on Mars, Jupiter, no interdependence of selves in community -and they are, comparatively, boring.

This self-impulse is the vital life impulse, the principal carrier of biological value. An organismic self is not a bad thing, nor is the defense of it, not ipso facto empirically or logically. Systemically put, the question is: are these good products the resultant of a bad process? If there is systemic disvalue, this must lie in an overextension or aberration of the self-impulse.

Every organism is full of 'selfish genes,' Richard Dawkins (1989) tells us. George Williams decries evolutionary nature because it 'can honestly be described as a process of maximizing short-sighted selfishness' (Williams 1988: 385). But a process that produces selves, and interrelates them in communities, need not be bad, nor one in which these selves reproduce their kinds, actualizing their own values.

The system evolves organisms that attend to their immediate somatic needs (food, shelter, metabolism) and that reproduce themselves in the very next generation. They have to be 'short-sighted.' In the birth-death-birth-death system a series of replacements is required. The organism must do this, it has no options; it is 'proper' for the organism to do this (Latin proprium, one's own proper characteristic). Somatic defense and genetic transmission are the only conservation activities possible to most organisms; they are necessary for all, and they must be efficient about it. The alleged selfishness is really the key to the systemic conservation of value intrinsic to the organism in the only manner possible and appropriate to it. Any particular organism, in the subroutines of this system, actualizes its own values and transmits these to the next generation (with variations). Although the organism is engaged in a short-range reproduction of its kind, the systemic processes are neither short-range and nor do they selfishly maximize only one kind. The system is three and a half billion years old; it has steadily produced new arrivals, replacements, and elaborations of kinds, going from zero to five (or ten) million species, through five (or 
Pages 67-86 in Willem B. Drees, ed., Is Nature Ever Evil? Religion. Science and Value, London: Routledge, 2003.

8

NATURALIZING

\author{
AND \\ SYSTEMATIZING \\ EVIL
}

\author{
Holmes Rolston, $\mathrm{HI}$
}

A common approach de-naturalizes evil - takes the evil out by claiming that natural things just are, without value being either present or absent. If one asks whether a tree is sad or glad, one is misunderstanding trees. If one asks whether evolution is good or evil, one is using irrelevant categories. Nature is a neutral substrate. Natural processes and products have the standing possibility of valuation or disvaluation when humans come on the scene. But matters of fact have to be kept in a different realm from matters of value.

This view is plausible for moral evil, in the strong sense of culpably depraved. Neither is nature morally praiseworthy. We humans do not take our moral standards from nature, nor should we fault nature as though it were moral. That is a category mistake.

My inquiry is about nonmoral evil, in the weaker sense, of events and processes, which, though not culpable agents, are bad, harmful, cruel, injurious. Here, too, often nature just is. When Comet Shoemaker-Levy crashed into Jupiter in 1994 and upset the flow bands, I was not prompted to ask questions of good and evil. There does not seem to be anything evil out there in space. The place to look is here on Earth. Orcas catch sea lions for food, and play with them, tossing the struggling lions into the air, prolonging their agony. I do not fault the killer whales, but I might ask whether the nature is evil that, through natural selection, results in the nature of such beasts.

I am not asking whether this is the best possible world, but more modestly whether this Earth is systemically prolific at increasing biodiversity and biocomplexity, and whether the evils here integrate well into those powers. Perspective is crucial.

\title{
Physics and biology
}

But there is another side to this. Agreeing that there is bad in biology, physicists reply that their nature is not value free, but quite valuable. Looking at nature systemically, we have discovered a 'fine-tuned' universe 


\section{HOLMES ROLSTON, III}

from astrophysics to nuclear physics, and a messy one from evolutionary and ecosystemic biology. Physics has made dramatic discoveries at astronomical and submicroscopic ranges. This universe originated fifteen billion years ago in a 'big bang' and has since been expanding. From the primal burst of energy, elementary particles formed, and afterward hydrogen, the simplest element, which serves as fuel for the stars. In the stellar furnaces all the heavier atoms were forged. Some stars subsequently exploded (supernovae). The heavier elements were collected to form, in our case, the solar system and planet Earth.

Physics has discovered that startling systemic interrelationships are required for these creative processes to work. Recent theory interrelates the two levels; astronomical phenomena such as the formation of galaxies, stars, and planets depend critically on the microphysical phenomena. In turn, the mid-range scales, where the known complexity mostly lies (on Earth, in ecosystems or human brains), depend on the interacting microscopic and astronomical ranges.

Change slightly the strengths of any of the four forces that hold the world together (the strong nuclear force, the weak nuclear force, electromagnetism, gravitation), change critical particle masses and charges, and the stars would burn too quickly or too slowly, or atoms and molecules, including water, carbon, and oxygen, or amino acids (building blocks of life) would not form or remain stable.

Astrophysicists and microphysicists have joined to discover that, in the explosion that produced our universe, what seem to be widely varied facts really cannot vary widely, indeed that many of them can hardly vary at all, and have the universe develop life and mind. We find a single blast (the big bang) fine-tuned to produce a world that produces us, when any of a thousand other imaginable blasts would have yielded nothing.

How the various physical processes are 'fine-tuned to such stunning accuracy is surely one of the great mysteries of cosmology,' remarks P.C.W. Davies. 'Had this exceedingly delicate tuning of values been even slightly upset, the subsequent structure of the universe would have been totally different.' 'Extraordinary physical coincidences and apparently accidental cooperation ... offer compelling evidence that something is "going on." ... A hidden principle seems to be at work' (1982: 90, 110). Maybe we will need to draw theological conclusions, maybe not. But naturalistically, at least cosmologically, this seems to be a good system, not value free at all, but valuable, value-able, able to generate value.

In biology, by contrast, the history of life on Earth is a random walk with much struggle and chance, driven by selfish genes, although biologists have also found that in this random walk order is built up over the millennia across a neg-entropic upslope, attaining in Earth's natural history the most complex and highly ordered phenomena known in the universe, such as ecosystems, organisms, and, above all, the human mind. 


\section{NATURALIZING AND SYSTEMATIZING EVIL}

So systemically we have a case of cognitive dissonance, a physical world that seems value free in some perspectives, valuable in others, and a biological world that seems fertile but clumsy, maybe evil.

\section{Order and disorder}

Perhaps the reason why all the good is in physics and the bad in biology is that all the order is in physics and all the disorder in biology. But the matter is complex. We are not going to get, and do not want, any law that says: order, more order, more and more order. Logically and empirically, there must be an interplay of order and disorder if there is to be autonomy, freedom, adventure, success, achievement, emergents, surprise, and idiographic particularity. In a world without chance there can be no creatures taking risks, and the skills of life would be very different, if indeed life - as opposed to mechanism - were possible.

But sceptics are not so sure. Yes, molecular biology is impressive for the order it has discovered. But no, when we turn to evolutionary biology, the processes get much more disordered. Evolutionary history has located the secret of life in natural selection operating over incremental variations, with the fittest selected to survive. The process is prolific, but no longer fine-tuned. On the contrary, it is make-shift.

The evolutionary course, far from being a directionally ordered whole, or having headings anywhere in its major or minor currents, rather wanders. It wanders in the first instance due to atomic and molecular chance (both relative and absolute) and, given these chancy mutational possibilities provided from the lower levels, it wanders in the second instance due to the nonselection for anything but mere survival, without bias toward progress, improvement, or complexity. The process is aimless, so it can bring evil as readily as it does good. Biologists survey the staggering array of fossil and surviving life forms, see it as full of struggling, chance, zigzag, and groping omnidirectionality, some trials happening to work, most failing, a very few of them eventuating in the ascent of neural forms.

Nevertheless, systemically, what most needs to be explained in biology is not the disorder, but the neg-entropic ascent. Biologists are much troubled by what account to give of any systemic, constructive forces that give a slope to evolution. (One might say that, at this point, the discipline is in disorder about order.) The physical world overall moves thermodynamically downhill, but now in bioscience we need an overall upslope force, or set of forces, a sort of biogravity that accounts not only for a survival drive but for the assembling and conservation of more diverse and also more advanced forms. With the passage of time and trials, there will, by ever more probability, be ever more salient constructions of life, enormous distances travelled upward. 
Systemically, there seems a mixture of inevitability and openness, so that one way or another, given the conditions and constants of physics and chemistry, together with the biased earthen environment, life will somehow both surely and surprisingly appear. Manfred Eigen, a thermodynamicist, concludes 'that the evolution of life ... must be considered an inevitable process despite its indeterminate course' (1971: 519). Life is destined to come, yet the exact routes it will take are open and subject to historical vicissitudes.

Now we can get the biology back together with the physics. Despite the fine-tuned and systemically well-ordered nature we were sketching, there is disorder too in physics, the quantum indeterminism. Often that has no import for our native ranges of experience. Any uncertainty will be statistically, or systemically, masked out. A macro-determinism remains, despite a micro-indeterminism. Stochastic processes at lower levels are compatible with determinate processes at upper levels.

But perhaps there are sometimes gross effects. In genetics, events at the phenotypic level are profoundly affected by events launched at the genotypic level, as with point mutations or genetic crossing over, affected by radiation subject to quantum effects. This may affect regulatory molecules, as when allosteric enzymes, which amplify processes a million times, are in turn regulated by modifier molecules, of which there may be only a few copies in a cell, copies made from a short stretch of DNA, where a few atomic changes can shift a whole reading frame. Indeed, by the usual evolutionary account, the entire biological tale is an amplification of increments, where microscopic mutations are edited over by macroscopic selective processes. These increments are most finely resolved into molecular evolutions.

If we turn from the random to the interaction possibilities in physics, we gain a complementary picture. Nature is not just indeterminate in random ways but is plastic enough for an organism to work its program on. An organism can coagulate affairs this way and not that way, in accord with its cellular and genetic programs. The macromolecular system of the living cell is influencing by its interaction patterns the behaviour of the atomic systems. The organism is fine-tuned at the molecular level to nurse its way through the quantum states by electron transport, proton pumping, selective ion permeability, DNA encoding, and the like. The organism via its information and biochemistries participates in forming the course of the micro-events that constitute its passage through the world.

The organism is responsible, in part, for the micro-events, and not the other way round. The organism has to flow through the quantum states, but the organism selects the quantum states that achieve for it an informed flow-through. The information within the organism enables it to act as a preference sieve through the quantum states, by interaction sometimes causing quantum events, sometimes catching individual chance events 


\section{NATURALIZING AND SYSTEMATIZING EVIL}

which serve its program, and thereby the organism maintains its life course.

The organism is a whole that is program-laden, a whole that executes its lifestyle in dependence on this looseness in its parts. There is a kind of downward causation which complements an upward causation, and both feed on the openness, if also the order, in the atomic substructures. The microscopic indeterminism provides a looseness through which the organism can steer itself by taking advantage of the fluctuations at the micro levels.

These organisms, over time, maintain themselves in their species lines. Adaptation is imperfect, but if it were perfect evolution would cease, nor could life track changing environments, nor could we have evolved to where we are. It is the imperfection that drives the world toward perfection, the disvalue that is necessary in the search for more value. Natural selection requires disvalues in its exploration for values, but selects against them, to leave the values in place, so far as this is possible under local genetic and ecological constraints.

Now a different perspective on this earthen stew strikes us. Complexity requires multiple distinct parts with multiple connections. Too much distinctness yields disorder, chaos, contingency. Too much connection yields rigidity, determinism, order. Complexity must be situated between order and disorder, or 'at the edge of chaos,' or, we might say, 'on the edge of evil' on either side. A spontaneously organizing system (= 'selforganizing) is one in which, over time, such complexity has appeared, is maintained, and may continue into the future.

This churn of materials, perpetually agitated and irradiated with energy, is not some problematic, indifferent, value-free substrate, but the prolific source. The neg-entropy is as objectively there as the entropy. Nor is the disordering entropy always bad, because in a world of perpetual construction there must be perpetual deconstruction. Systemically, the achievements are as real as the drifting cycles and random walks. Genetic organisms have been making biological discoveries superposed on the geomorphic and astronomical givens. Against the indifference, the results have been prolific, five million species flourishing in myriads of diverse ecosystems.

Life makes matter count. It loads the dice. Biological events are superintending physical ones. Biological nature takes advantage of physical nature. We gain space for the higher phenomena which physics had elected to leave out.

\section{Law and history}

What the random walk omits is the cybernetic, hereditary capacity of organisms to acquire, store, and transmit new information over historical 


\section{HOLMES ROLSTON, III}

time. Organisms start simple and some of them end up complex; there are trends over longer-range time scales because something is at work additionally to tracking drifting environments. The life process is drifting through an information search, locking onto discoveries. With such a conclusion we pass from a law-like world into a historical world, or more technically from a nomothetic system to an idiographic system.

The highest values are in story, not law, in history not repeatability. Only in a spontaneously generating story can there be such adventure and novelty. The familiar scientific word for this is 'evolution,' but the better word is 'history.' In physics and chemistry one seeks laws and initial conditions with which one can predict the future. But in biology any such laws become only regularities, subject to surprises. The novel discoveries, coded in the genetics, have not only revised the initial conditions, they have also revised the previous regularities. The disorder and openness generate history. The future is not like the past; there are developing story lines.

Frances Crick complains that biology has no 'elegance.' Organisms evolve happenstance structures and wayward functions that have no more overarching logic than the layout of the Manhattan subway system (Crick 1988: 6, 137-42). Stephen Jay Gould insists that the panda's thumb is evolutionary tinkering and that orchids are 'jury-rigged' (Gould 1980: 20). Evolution works with what is at hand, and makes something new out of it.

But what is so disvaluable about that? The achievements of evolution do not have to be optimal to be valuable; and if a reason that they are not optimal is that they had to be reached historically along story lines, it is more valuable to have history plus value as storied achievement than to have 'elegant' optimal solutions without history or autonomy. Organismic vitality is better than regimented simplicity. The elegance of the thirty-two crystal classes is not to be confused with the elegance of an old-growth forest.

Take Figures 8.1 and 8.2 on the following pages and suppose they looked instead like Figures 8.3 and 8.4.

Such a world would be impressive, but rather boring, less interesting than the world in which we in fact find ourselves. It would have too much system and too little adventure, too much law and no history.

Something is increasingly learned across evolutionary history: how to make more kinds and more complex kinds. This may be a truth about natural history, even if neo-Darwinism is incompetent to say much about how this happens. Cold and warm fronts come and go, so do ice ages. There are rock cycles, orogenic uplift, erosion, and uplift again. But there is no natural selection there, nothing is competing, nothing is surviving, nothing has adapted fit, and biology seems different. All those climatological and geomorphological agitations continue in the Pleistocene period more or less like they did in the Precambrian, but the life story is not the same all over again. Where once there were no species, now there are five 


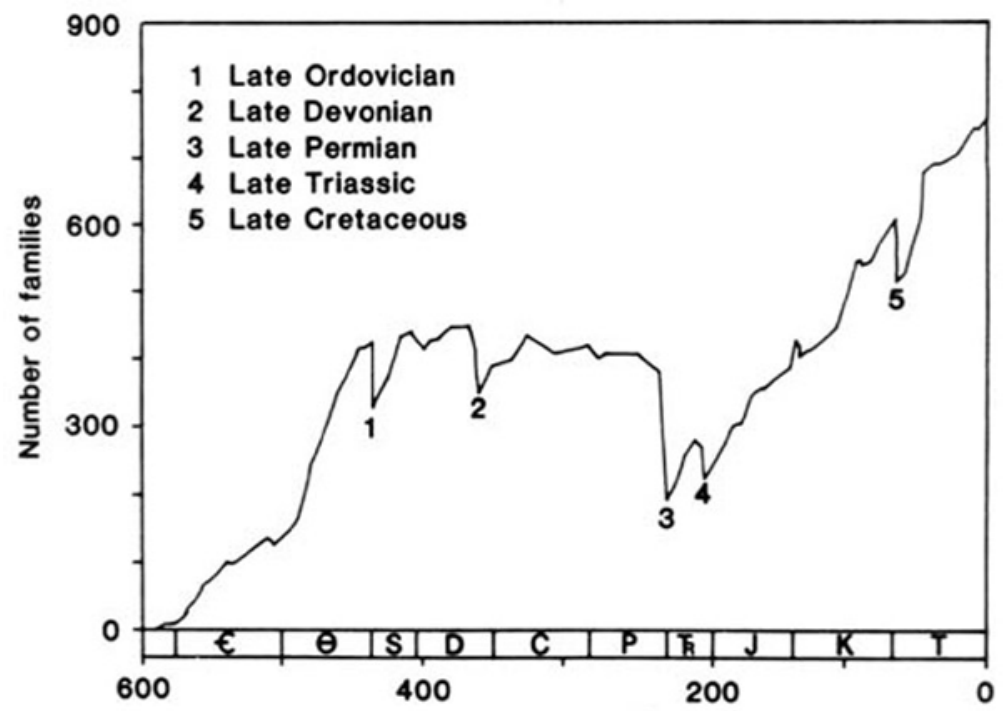

Geological time ( $10^{6}$ years $)$

Figure 8.1 Standing diversity through time for families of marine vertebrates and invertebrates, with catastrophic extinctions

Source: Reprinted with permission from Raup and Sepkoski, 1982, p. 1502. Copyright 1982 American Association for the Advancement of Science.

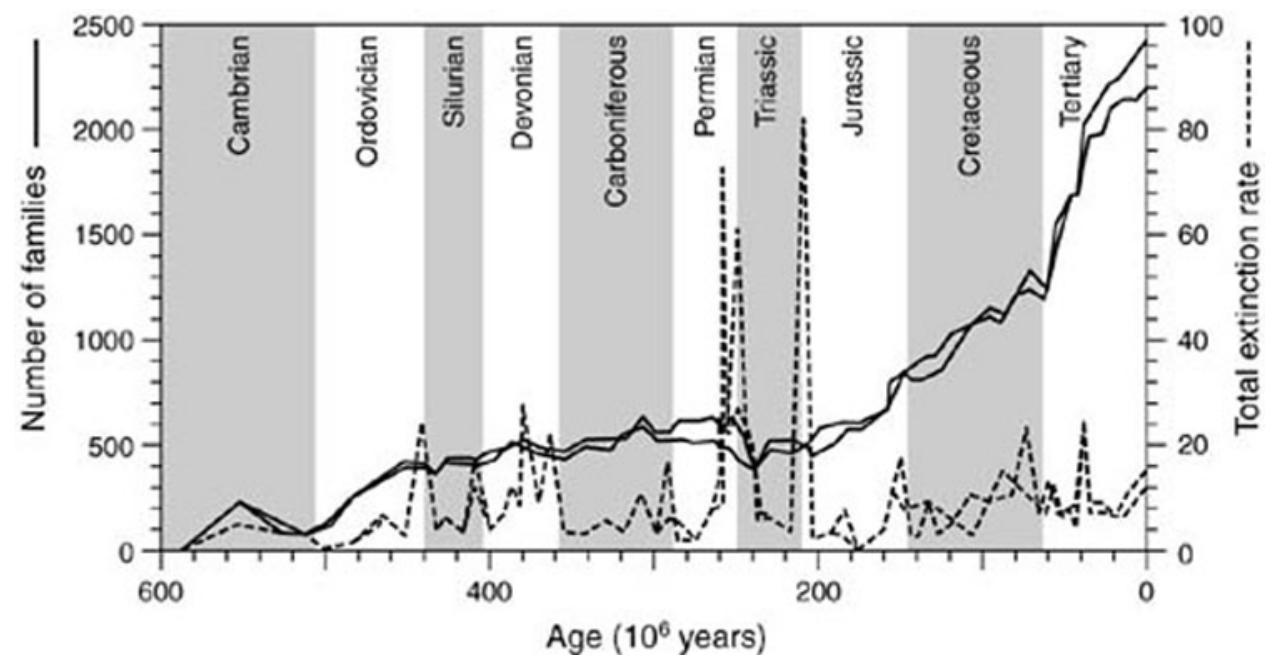

Figure 8.2 Proliferation of number of families on Earth, continuing through major extinctions. The double lines in both the number of families and the extinction rate represent maximum and minimum estimates.

Source: Reprinted with permission from Myers, 1997, p. 598, based on Nee and May, 1997.

Copyright 1997 American Association for the Advancement of Science. 


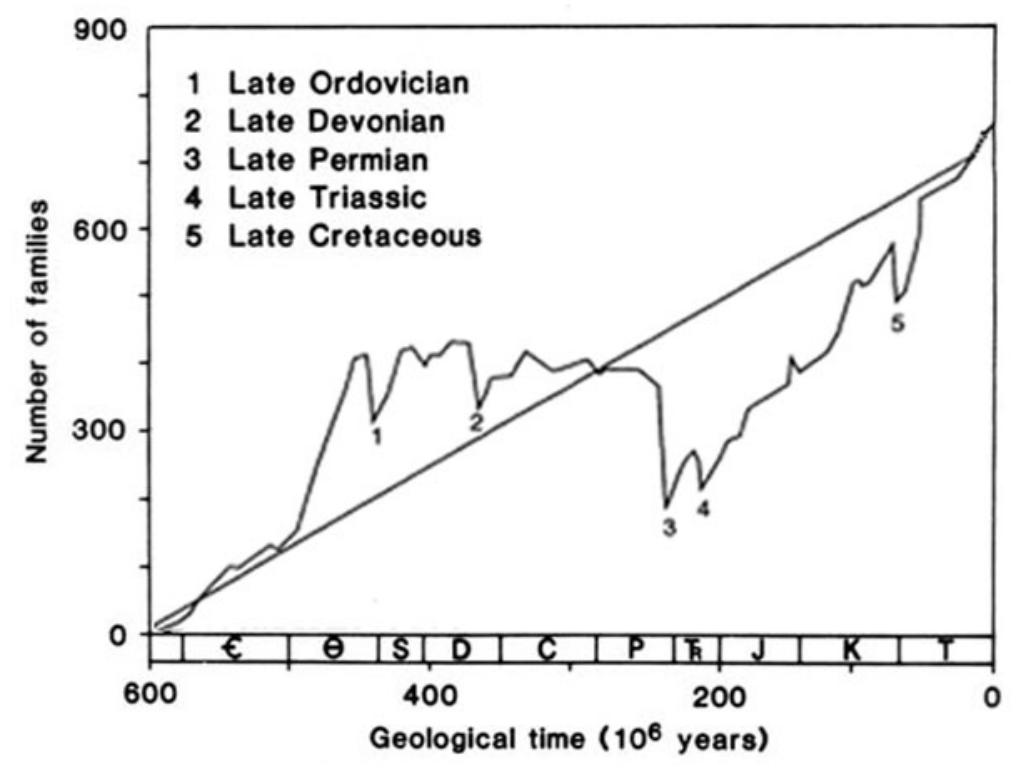

Figure 8.3 Supposed linear development of marine diversity

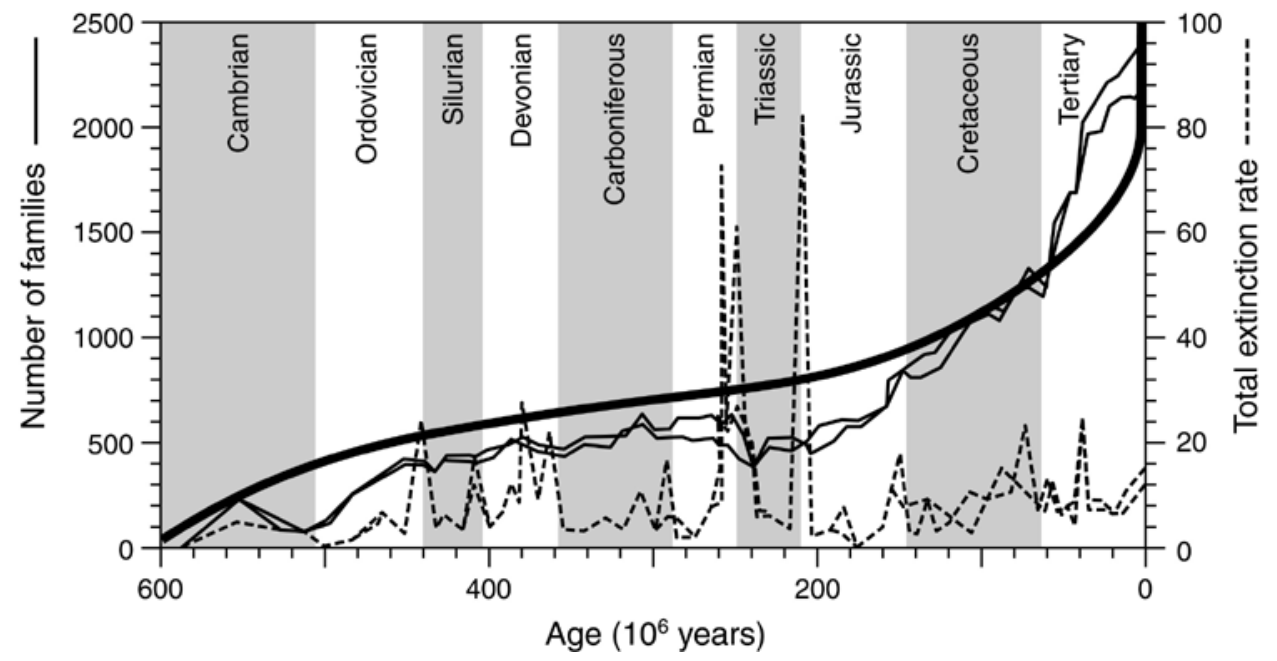

Figure 8.4 Supposed more orderly proliferation of life on Earth 


\section{NATURALIZING AND SYSTEMATIZING EVIL}

to ten million. On average, and environmental conditions permitting, the numbers of life forms start low and end high.

J.W. Valentine concludes for marine environments: 'A major Phanerozoic trend among the invertebrate biota of the world's shelf and epicontinental seas has been towards more and more numerous units at all levels of the ecological hierarchy. ... The biosphere has become a splitter's paradise' (Valentine 1969: 706). There is 'a gradually rising average complexity' (Valentine 1973: 471). The story of terrestrial life is even more impressive, because the land environment is more challenging. Reptiles can cope in a broader spectrum of humidity conditions than amphibians. Mammals can cope in a broader spectrum of temperature conditions than reptiles. Genetic and enzymatic control is surpassed by neural networks and brains; there are increases in sentient capacity, locomotion, acquired learning, communication, language acquisition, and in manipulation.

There are increases in capacities for centralized control (neural networks, brains that surpass mere genetic and enzymatic control), increases in capacities for sentience (ears, eyes, noses, antennae), increases in locomotion (muscles, legs, wings), in capacities for manipulation (arms, hands, opposable thumbs), increases in acquired learning (feedback loops, synapses, memory banks), increases in communication and language acquisition. Nothing seems more evident over the long ranges than that complexity has increased, developing historically. In the Precambrian there were microbes; in the Cambrian Period trilobites were the highest life form; the Pleistocene Period produced persons.

Francisco J. Ayala concludes: 'Progress has occurred in nontrivial senses in the living world because of the creative character of the process of natural selection' (Ayala 1974: 353). Some will find that this is a 'law' of evolution. If so, this is a startling law: incessantly generate more biodiverse and complex kinds. Such law passes over into history.

\section{Self and community}

There are 'selves' - biological organismic identities to be preserved. No such selves exist, except in communities, ecosystems. It is difficult to imagine much life without a cellular character, difficult to imagine much biodiversity or biocomplexity without life being multicellular. It is difficult to imagine much organismic differentiation and specialization of functions and skills without a characteristic 'self.' To optimize a vital 'self with a unique genetic self over a landscape of challenges, stabilities, and contingencies is really to develop a story line.

Further, one 'self cannot do it all. No 'self has 'aseity' (total self-containment). A lot of diversity, with autonomy, will mean a lot of interdependencies, feedback loops, feed forward loops, indeed a lot of feed loops. Systemically, it seems impossible - on this Earth at least - to have 


\section{HOLMES ROLSTON, III}

animal biology without 'feeding,' value capture, biotic resources such as energy and structural materials that were preformed outside oneself. It cannot be a bad thing for an organism to depend on another for skills or metabolisms it lacks, or else humans (who cannot photosynthesize) eating plants (which can) would be an evil. All heterotrophs of spectacular evolutionary achievement live in dependence on plants. A photosynthetic world would be a largely immobile world. In turn, autotrophs quite depend on animals for their carbon dioxide. Cycles and hypercycles build up.

The heavens are fine-tuned, and we are happy about the beauty and regularity there. But the heavens are also a world in which there is no caring. Earth, with its selves, is a world in which things can get hurt. You cannot be helped in a world where you cannot be hurt; you cannot live biologically in a world in which you cannot die; you cannot succeed in a world in which you cannot fail. Notice too that there is no community on the moon, on Mars, Jupiter, no interdependence of selves in community and they are, comparatively, boring.

This self-impulse is the vital life impulse, the principal carrier of biological value. An organismic self is not a bad thing, nor is the defense of it, not ipso facto empirically or logically. Systemically put, the question is: are these good products the resultant of a bad process? If there is systemic disvalue, this must lie in an overextension or aberration of the self-impulse.

Every organism is full of 'selfish genes,' Richard Dawkins (1989) tells us. George Williams decries evolutionary nature because it 'can honestly be described as a process of maximizing short-sighted selfishness' (Williams 1988: 385). But a process that produces selves, and interrelates them in communities, need not be bad, nor one in which these selves reproduce their kinds, actualizing their own values.

The system evolves organisms that attend to their immediate somatic needs (food, shelter, metabolism) and that reproduce themselves in the very next generation. They have to be 'short-sighted.,' In the birth-death-birthdeath system a series of replacements is required. The organism must do this, it has no options; it is 'proper' for the organism to do this (Latin proprium, one's own proper characteristic). Somatic defense and genetic transmission are the only conservation activities possible to most organisms; they are necessary for all, and they must be efficient about it. The alleged selfishness is really the key to the systemic conservation of value intrinsic to the organism in the only manner possible and appropriate to it. Any particular organism, in the subroutines of this system, actualizes its own values and transmits these to the next generation (with variations). Although the organism is engaged in a short-range reproduction of its kind, the systemic processes are neither short-range and nor do they selfishly maximize only one kind. The system is three and a half billion years

old; it has steadily produced new arrivals, replacements, and elaborations of kinds, going from zero to five (or ten) million species, through five (or 


\section{NATURALIZING AND SYSTEMATIZING EVIL}

ten) billion turnover species in a kaleidoscopic panorama. The result is a quite dramatic story, the history we were celebrating.

The genes seek only survival, but the story is of arrivals. The environmental system in which these selfish genes are embedded not only irritates them, producing an agitated effort at competitive survival, but also induces them, sometimes, to pass over into something higher. Species increase their kind; but ecosystems increase kinds.

In this kind of system, there will be, by logical and empirical necessity, bad things that happen to individuals. If an animal has one hundred available actions (locating a prey, stalking a prey, catching it, killing it, defending its place in the dominance hierarchy), and the animal needs to sequence ten of these, there are $100^{10}$ combinations available, an astronomical number. Unfolding such possibilities, it is inconceivable that such creatures will not make mistakes and have accidents, some of them tragic.

In the woods one comes upon the lovely nest of an ovenbird, built on the ground of grasses folded over like an old-fashioned oven. Inside are the chicks, but, alas, crushed, for they have been stepped on by a passing deer. That can seem a gratuitous evil. The deer gains nothing by the accident; had it stepped elsewhere nothing would have been really different for it. The bird has only lost.

But in a world where ovenbirds are on their own, and deer are freeranging, these trajectories are sometimes going to clash. A world with creaturely integrities could not be otherwise, though a less valuable world of marionettes might. Windblown seeds fall, some on rock or unsuitable ground. Some get eaten. Some sprout to get killed by a frost; some die when the rains fail. But some succeed, and their species lines perpetuate in their communities. It cannot be otherwise in the prolific combination of order and disorder, law and history, self and community we enjoy on Earth.

But the caring self is on its own in a nature that doesn't care. Yes, and the same nature provides life support. As a species, organisms get selected for those functions and skills that enable them to do better in their niches, and what is so uncaring about that? Selection for adapted fit is a strange kind of indifference.

\section{Conflict and resolution}

In a world in which there are 'selves,' there are going to be conflicts between these 'selves,' as surely as there must be some cooperation among them. There are going to be winners and losers. If the environment can be good, that brings also the possibility of deprivation as a harm. To be alive is to have problems. Things can go wrong just because they can also go right. Organisms will hit limits, and these limits are, from the viewpoint of that organism, 'bad' for them. But these limits are not necessarily a bad 


\section{HOLMES ROLSTON, III}

thing, but rather are likely to be a good thing systemically, and even good for the species of which the organism is a member.

If irritability seems at first an unwelcome, adventitious intruder into the life project, by a switch of gestalts it becomes part of the biologic and logic of meanings. All advances come in contexts of problem solving, with a central problem in sentient life the prospect of hurt. We do not really have available to us any coherent alternative models by which, in a painless world, there might have come to pass anything like these dramas of nature that have happened. There is none of this on Mars, Jupiter.

Injury, harm, disease, and misfortune will come to individuals as a logical and empirical result of the character of the system. Sceptics will attempt a case by case analysis, and have little problem finding this or that event that is counterproductive, hurt with no beneficial result. It would have been a better world if the deer had not crushed the ovenbird's nest. Yes, you can sneak out such events here and there and not make any difference, systemically. But it is logically and empirically impossible systemically to eliminate all such events, or even foundationally significant numbers of such events, and have autonomous selves in the system. You cannot take out this class of events and have the richness of lives that has eventuated on Earth.

The system summarizes the lives of individuals in their conflict and resolution, using this to innovate by spinning out the biodiversity and biocomplexity we treasure. Failure in this system is 'evil' for each individual, but the summarizing and innovating system has not failed, not yet at least for 3.5 billion years.

Still, sceptics will insist: the relentless struggle to survive is an evil in the system. Adapted fit seems a good thing, but the shadow side is how each organism is doomed to eat or be eaten, to stake out what living it can in competition with others. Perhaps there is more efficiency than waste, more fecundity than indifference, but each organism is ringed about with competitors and limits, forced to do or die. Each is set as much against the world as within it. Physical nature, from which are wrested the materials of life, is brute fact and brutally there, caring naught and always threatening. Organic nature is savage; life preys on life. Predation of the orcas on the sea lions is difficult to watch without wincing.

Nature as a jungle does not mean that there are no valuers in the wild; it portrays too many claimants contesting scarce worth. Perhaps the most we can conclude is that local achievements of value are wrested out of a disvaluable place? But systemically, the truth lies deeper. The context of creativity logically and empirically requires this context of conflict and resolution. An environment entirely hostile would slay us; life could never have appeared within it. An environment entirely irenic would stagnate us; advanced life, including human life, could never have appeared there either. Oppositional nature is the first half of the truth; the second is that 


\section{NATURALIZING AND SYSTEMATIZING EVIL}

none of life's heroic quality is possible without this dialectical stress. Take away the friction, and would the structures stand? Would they move? Muscles, teeth, eyes, ears, noses, fins, legs, wings, scales, hair, hands, brains - all these and almost everything else comes out of the need to make a way through a world that mixes environmental resistance with environmental conductance. Half the beauty of life comes out of endurance through struggle.

What is this struggle but a history of transvaluing disvalues into values? Both are objectively present in nature, nor is the struggle a zero sum game, nor null of value; rather, the struggle is prolific creativity. Systemically, there is as much reason to think that the outcome of all this struggle is a good thing as a bad thing, especially if seen as a struggle for adapted fit and to thrust life on. Charles Darwin felt this keenly. The process is 'clumsy, wasteful, blundering, low, and horribly cruel' (quoted in De Beer 1962: 43). But Darwin concluded his Origin of Species by finding a 'grandeur in this view of life' (1872: 484).

John Stuart Mill cursed nature as an 'odious scene of violence' ([1874] 1969: 77, 398). Thomas Huxley admonished: 'Let us understand, once for all, that the ethical process of society depends, not on imitating the cosmic process, still less on running away from it, but in combating it' ([1893] 1946: 82). George Williams hates nature: 'Mother Nature is a wicked old witch!' (1993). Over evolutionary history, with the diversity, complexity, and creativity we have celebrated, there emerges the capacity to suffer. Indeed the story could be titled, perversely, 'The Evolution of Suffering.' Each seeming advance - from plants to animals, instinct to learning, ganglia to brains, sentience to self-awareness, herbivores to carnivores steps up the pain. Struggle deepens through time into suffering. In chemistry, physics, astronomy, geomorphology, meteorology nothing suffers; in botany life is stressed, but only in zoology does pain emerge. Is not this the evolution of increasing disvalue? A more adequate answer is that struggle is the dark side of creativity. The system, from the perspective of the individual, is built on competition and premature death. Seen systemically, that is the generating and testing of selves by conflict and resolution, such values required to be both prolific and adapted fits.

\section{Generate and test}

The standard account is that evolution is blind. Random variations bubble up from the genetic level. Those few that are accidentally useful are selected; most, worthless, are discarded; some, to which even natural selection is blind, since they produce no differential survival rates, remain and result in genetic drift. Zig here, zag there, organisms stumble onto a life program. 'The evolutionary process,' says George Williams, 'is abysmally stupid' (Williams 1988: 400). 


\section{HOLMES ROLSTON, III}

But genetic creativity is really quite startling in what it has produced: many millions of species all the way from microbes to persons, coded for coping in all kinds of environments, and we may want to think further about whether it is something more than a random walk. Genetic vitality may be in fact a sophisticated problem-solving process.

In reproduction, the genetically originated novelties are formed in a shuffle that is far from chaotic. Only those variations are tested and selected that are more or less functional. The organism typically only probes the nearby space for possible directions of development. Mutators and antimutators increase or trim the mutation rates as a function of population stresses. Repair mechanisms snip out certain genetic errors, and thus eliminate some variation. Individual genetic sets are adept at pumping out their own disorder. But they do not pump out all novelty; that would cease evolutionary development and lead to extinction (Gardner 1975: 267-303).

Specific mutations are non-directed, but the rate and place at which they occur is partially regulated. There is a tendency for genes to sort in blocks, often pre-tested blocks (Mayr 1976). There is a shake-up of the genes under environmental stress, so that the fastest evolution toward variant forms, often more highly organized forms, takes place almost explosively after major geologic crises.

These trials and ancestral forms are subject to optimizing pressures and tested for their performances. What nature conserves is the best of its constructions within a particular ecological niche. Mutation scans for new 'ideas,' and natural selection throws out the trash and saves the gems. Evolutionary achievement is a rudimentary form of cognition. In terms of human imagination and logic, it is not always a waste but sometimes an index of creativity to cast forth a thousand ideas so as to sort out the single best one.

Systemically, the gestalt begins to change. The evolutionary process, far from being irrational, is a prototype of the only kind of rationality that we know. There is a logic to it, not only to its information conservation, but to its random exploration and problem solving. The speciation process is drifting through an information search, and edited for its discoveries of information. This editing is for survival, but it also scans and produces new arrivals on a climb toward complexity, sentience, and, eventually, mind. It is the production of errors that produces knowledge. The whole system is a context of instruction. Natural selection at its critical turnings will select those mutations that are superior and reproduce them. It tends in that direction, even though it does not intend it. Thus the seeming absurdity of the random element can be put in a more intelligible gestalt, where it becomes a precondition of epistemic development.

Contemporary geneticists are insisting that we misperceive this process if we think of it as blind. There is a vast array of sophisticated enzymes to cut, splice, digest, rearrange, mutate, reiterate, edit, correct, translocate, invert, 


\section{NATURALIZING AND SYSTEMATIZING EVIL}

and truncate particular gene sequences. John H. Campbell concludes: 'Cells are richly provided with special enzymes to tamper with DNA structure/ enzymes that biologists are extracting for genetic engineering. But this 'engineering' is already going on in spontaneous nature. 'Gene-processing enzymes also engineer comparable changes in genes in vivo. ... We have discovered enzymes and enzyme pathways for almost every conceivable change in the structure of genes. The scope for self-engineering of multigene families seems to be limited only by the ingenuity of control systems for regulating these pathways.' These pathways may have 'governors' that are 'extraordinarily sophisticated.' 'Self-governed genes are "smart" machines in the current vernacular sense. Smart genes suggests smart cells and smart evolution, ... the promise of radically new genetic and evolutionary principles' (Campbell 1983: 408-10, 414).

So far from disparaging the blind groping of genes, computer scientists may deliberately seek to imitate a similar process on their unconscious computers. Some sophisticated programs use what are called 'genetic algorithms' (Goldberg 1989; Mühlenbein, Gorges-Schleuter and Krämer 1988). Such algorithms involve recombining partial solutions to a problem in order to generate improved solutions. Genetic problem solving, then, does not seem so tinkering, jury-rigged, and blind. On the contrary, it is remarkably like what some of the smartest scientists are doing. There is valuable problem solving taking place. Maybe there is more elegance than we first thought. Certainly there are remarkable success stories.

\section{Nature and grace}

Biology and religion have increasingly joined in recent years in admiration for this marvellous planet. We see in nature, beyond any natural laws, a kind of grace. Grace, most will think, belongs in the theological tradition, where goodness appears that one has no cause to expect, a salvation that one has not merited, a favour that one does not deserve. But in nature too there is surprising goodness, something given that has no justification in law or logic, even if there does seem some heading or destiny filling up the world with these wonders.

Classical theology frequently separated nature and grace, a sometimes useful contrast. But today, systemically in natural history, we can combine nature and grace at new levels of insight and intensity. Life is a kind of gift. There is startling fertility, genesis. This is among the best established facts. This creativity we inherit, and the values this generates, are the ground of our being, not just the ground under our feet. Nature is grace, whatever more grace may also be. Earth is an expression point of a mysterious power in cosmic nature.

Life persists because it is provided for in the evolutionary and ecological Earth system. Earth is a kind of providing ground, where the life epic is 


\section{HOLMES ROLSTON, III}

lived on in the midst of its perpetual perishing, life arriving and struggling through to something higher. When J.B.S. Haldane was asked whether he had concluded anything about the character of life from his long studies in biology, he replied that the marks of biological nature were its 'beauty,' 'tragedy,' and 'inexhaustible queerness' (1932, 1966: 167-9).

This beauty approaches the sublime; the tragedy is perpetually redeemed with the renewal of life, and the inexhaustible queerness recomposes as the numinous. If anything at all on Earth is sacred, it must be this enthralling creativity that characterizes our home planet. So the secular this present, empirical epoch, this phenomenal world, studied by science urges us on a spiritual quest. If there is any holy ground, any land of promise, this promising Earth is it. Today we say: life is generated 'at the edge of chaos.' Yesterday, John said: 'The light shines in the darkness, and the darkness has not overcome it' (John 1:5).

Annie Dillard rebels against Earth: 'I came from the world, I crawled out of a sea of amino acids, and now I must whirl around and shake my fist at that sea and cry shame' (Dillard 1974: 180). But if I were Aphrodite, rising from the sea, I think I would turn back to reflect on that event and raise both hands and cheer. And if I came to realize that my rising out of the misty seas involved a long struggle of life renewed in the midst of its perpetual perishing, I might well fall to my knees in praise. Out of physical premises one derives biological conclusions, and, taking these as premises in turn, one derives psychological conclusions, which, recompounded again, yield spiritual conclusions. This kind of logic seems more story than argument; the form of argument is not so much rational as, to use a religious word, incarnational, since each step has to be embodied. Story is a better category than law, much less randomness, when one wants to get more out of less. If one tries to interpret the world as law plus initial conditions, there is little plot. If one tries to interpret the world as statistical probabilities, there is little story.

Science has disenchanted natural history, but this only increases the mystery. The story is quite fantastic, except that it is true. Maybe the best category, systemically updated, is that of miracle. Moses thought that the burning bush, not consumed, was quite a miracle. We hardly believe any more in that sort of supernatural miracle; science has made such stories incredible. But what has it left instead? A self-organizing photosynthesis driving a life synthesis that has burned for millennia, life as a strange fire that outlasts the sticks that feed it. This is hardly a phenomenon less marvellous, even if we no longer want to say that it is miraculous. Indeed, in the original sense of 'miracle' - a wondrous event, without regard to the question whether natural or supernatural - photosynthesis and the life it supports is the secular equivalent of the burning bush.

The bush that Moses watched was an individual in a species line that had perpetuated itself for millennia, coping by the coding in its DNA, 


\section{NATURALIZING AND SYSTEMATIZING EVIL}

fuelled by the sun, using cytochrome-c molecules several billion years old, and surviving without being consumed. To go back to the miracle that Moses saw, a bush that burned briefly without being consumed, would be to return to something several orders of magnitude less spectacular.

Thanks to the molecular biologists and geneticists, we increasingly know how this works; but is this an account that de-mystifies what is going on? The account we have is, if you like, a naturalistic account, but this nature is pretty spectacular stuff, a remarkable 'given,' even if you dislike thinking it might be a 'gift.' Yes, there is this spinning round of trillions of molecules, organizing themselves into a code for life, and executing this in a coping individual; but is there anything that suggests that such prolific nature is its own self-sufficient explanation?

Every life is an unceasing adventure in endowment and risk, and all organic being is constituted - to employ a scientific metaphor - in a mixture of environmental conductance and resistance, where the world is both resource and threat. To adapt the Psalmist's religious metaphor, life is lived in green pastures and in the valley of the shadow of death, nourished by eating at a table prepared in the midst of its enemies.

\section{Cruciform creation}

The root idea in the word 'nature' is 'birthing,' of a woman in labour (Greek natans, giving birth). Birth is a transformative experience where suffering is the prelude to, the principle of, creation. There is struggling through to something higher. Death in vivo is death ultimately; death in communitatis is death penultimately but life regenerated ultimately: life, death, and regeneration. Life is the first mystery that comes out of earthen nature, and death a secondary one. But death comes as surely as life to all higher organisms. Even the lower forms that reproduce by cell fission or by generating offshoots may and do die. So the great value, life, is countered by the great disvalue. For each organism, the last word is destruction.

But we are trying to see nature systemically, where death is not the last word - at least it has never yet been across three and a half billion years. Death is the key to replacement with new life. If nothing much had ever died, nothing much could have ever lived. Just as the individual overtakes, assimilates to itself, and discards its resource materials, so the evolutionary wave is propagated onward, using and sacrificing particular individuals, who are employed in, but readily abandoned to, the larger currents of life. Thus the pro-life evolution both overleaps death and seems impossible without it. Death is part of the life cycle, not life part of the death cycle.

The death of the organism feeds into the non-death of the species. Only by replacements can the species track the changing environment; only by replacements can they evolve into something else. Species sometimes do 


\section{HOLMES ROLSTON, III}

die, go extinct without issue, but they are often transformed into something else, new species; and, on average, there have been more arrivals than extinctions - the increase of both diversity and complexity over evolutionary history.

These experiences of the power of survival, of new life rising out of the old, of the transformative character of suffering, of good resurrected out of evil, experiences of the harshness of nature invite us systemically toward a natural theology, and one congenial with Christian theology. Christianity seeks by a doctrine of providence to draw all affliction into the divine will. This requires penetrating backward from a climaxing cross and resurrection to see how this is so. Nature is intelligible. Life forms are logical systems. But nature is also cruciform. The world is not a paradise of hedonistic ease, but a theatre where life is learned and earned by labour. Life is advanced not only by thought and action, but also by suffering, not only by logic but also by pathos.

The Greek word is 'pathos,' suffering, and there are pathologies in nature, such as the diseases of parasitism. But pathology is only part of the disvalue; even in health there is suffering. Life is indisputably prolific; it is just as indisputably pathetic, almost as if its logic were pathos, as if the whole of sentient nature were pathological. This pathetic element in nature is seen in faith to be at the deepest logical level the pathos in God. God is not in a simple way the Benevolent Architect, but is rather the Suffering Redeemer. The whole of the earthen metabolism needs to be understood as having this character. The God met in physics as the divine wellspring from which matter-energy bubbles up, as the upslope epistemic force, is in biology the suffering and resurrecting power that redeems life out of chaos. All have 'borne our griefs and carried our sorrows.'

The abundant life that Jesus exemplifies and offers to his disciples is that of sacrificial suffering through to something higher. There is something divine about the power to suffer through to something higher. The Spirit of God is the genius that makes alive, that redeems life from its evils. The cruciform creation is, in the end, deiform, godly, just because of this element of struggle, not in spite of it. There is a great divine 'yes' hidden behind and within every 'no' of crushing nature. Redemptive suffering is a model that makes sense of nature and history. So far from making the world absurd, suffering is a key to the whole, not intrinsically, not as an end in itself, but as a transformative principle, transvalued into its opposite. The capacity to suffer through to joy is a supreme emergent and an essence of Christianity. Yet the whole evolutionary upslope is a lesser calling of this kind, in which renewed life comes by blasting the old. Life is gathered up in the midst of its throes, a blessed tragedy, lived in grace through a besetting storm.

Biblical writers rejoice in nature; they also speak of nature labouring in travail. 'Travail,' 'birthing,' in fact, is a key to understanding these evils. 


\section{NATURALIZING AND SYSTEMATIZING EVIL}

Paul writes that 'the whole creation has been groaning in travail together until now' (Romans 8:22). That is archaic in the antique sense, and equally archaic in the foundational sense: a cruciform creation. But note that Paul nowhere says - what is usually understood, indeed what Paul may also have believed - that this subjecting to suffering was a result of human sin. 'Groaning in travail' is in the nature of things from time immemorial. Such travail is the Creator's will, productive as it is of glory.

We have tried to see into the depths of what is taking place in natural history. The view here is not panglossian; it is a sometimes tragic view of life, but one in which tragedy is the shadow of prolific creativity. That is the case, and the biological sciences - evolutionary history, ecology, molecular biology - can be brought to support this view, although neither tragedy nor creativity are part of their ordinary vocabulary. Since the world we have, in its general character, is the only world logically and empirically possible under the natural givens on Earth - so far as we can see at these native ranges that we inhabit - this world that is, ought to be. A world without blood would be poorer, but a world without bloodshed would be poorer too, both less rich in biodiversity and less divine.

\section{References}

Ayala, F.J. (1974) 'The Concept of Biological Progress', in F.J. Ayala, T. Dobzhansky (eds.), Studies in the Philosophy of Biology, New York: Macmillan, 339-55.

Campbell, J.H. (1983) 'Evolving Concepts of Multigene Families', in [no named ed.] Isozymes: Current Topics in Biological and Medical Research, Volume 10: Genetics and Evolution, New York: Alan R. Liss, 401-17.

Crick, F. (1988) What Mad Pursuit: A Personal View of Scientific Discovery, New York: Basic Books.

Darwin, C. (1872) The Origin of Species, New York: Collier Books

Davies, P.C.W. (1982) The Accidental Universe, New York: Cambridge University Press.

Dawkins, R. (1989) The Selfish Gene, new edition, New York: Oxford University Press.

De Beer, G. (1962) Reflections of a Darwinian, London: Thomas Nelson and Sons.

Dillard, A. (1974) Pilgrim at Tinker Creek, New York: Bantam Books.

Eigen, M. (1971) 'Selforganization of Matter and the Evolution of Biological Macromolecules', Die Naturwissenschaften 58: 465-523.

Gardner, E.J. (1975) Principles of Genetics, 5th edition, New York: John Wiley.

Goldberg, D. (1989) Genetic Algorithms in Search ${ }_{9}$ Optimization, and Machine Learning, Reading, MA: Addison Wesley.

Gould, S.J. (1980) The Panda's Thumb, New York: W.W. Norton.

Haldane, J.B.S. (1932, 1966) The Causes of Evolution, Ithaca: Cornell University Press.

Huxley, T.H. [1893] (1946) 'Evolution and Ethics,' in T.H. Huxley and Julian Huxley, Evolution and Ethics, London: Pilot Press. 


\section{HOLMES ROLSTON, III}

Mayr, Ernst (1976) Evolution and the Diversity of Life, Cambridge, MA: Harvard University Press.

Mill, J.S. (1874) 'Nature', in Collected Works, vol. 10, Toronto: University of Toronto Press, 1969, pages 1963-77.

Mühlenbein, H., Gorges-Schleuter, M. and Krämer, O. (1988) 'Evolution Algorithms in Combinatorial Optimization', Parallel Computing 7: 65-85.

Myers, Norman (1997) 'Mass Extinction and Evolution', Science 278: 597-8.

Nee, Sean and May, Robert M. (1997) 'Extinction and the Loss of Evolutionary History', Science 278: 692-4.

Raup, David M. and Sepkoski, Jr., J. John (1982) 'Mass Extinctions in the Marine Fossil Record', Science 215: 1501-3.

Valentine, J.W. (1969) 'Patterns of Taxonomic and Ecological Structure of the Shelf Benthos during Phanerozoic Time', Paleontology 12: 684-709.

- (1973) Evolutionary Paleoecology of the Marine Biosphere, Englewood Cliffs, NJ: Prentice-Hall.

Williams, G.C. (1988) 'Huxley's Evolution and Ethics in Sociobiological Perspective', Zygon: Journal of Religion and Science 23: 383-407.

- (1993) 'Mother Nature is a Wicked Old Witch', in Matthew H. Nitecki and Doris V. Nitecki (eds.) Evolutionary Ethics, Albany: State University of New York Press, 217-31. 